\title{
OPTIMALISASI GITHUB UNTUK SOFTWARE PROJECT MANAGEMENT DENGAN MEMANFAATKAN NOTIFIKASI SMS
}

\author{
Syarif Hidayatulloh \\ Fakultas Teknik, Universitas BSI \\ Jalan Sekolah Internasional No.1-6 Antapani Bandung 40282 \\ syarif.sfq@bsi.ac.id
}

\begin{abstract}
- software project management is the art and science of planning and supervision in software projects. On project management software many emerging constraints that could result in his development and software development. One of the key points in a project the software repository is the time it takes to comment on, add and merge source code. Rapid feedback to make the members of a software project team was pleased to contribute in a software project. Problems on Github repository is when the notification was delivered via the web and email are not directly addressed because the members of the project management software rarely check emails. The methods used in this study is a literature study and experiments of different cases in the article, book or paper that discusses how to implement project management software quality so the software project goals can be achieved. Conclusion the results of the research that has been done is to apply the SMS notification on Github is expected to further speed up the interaction and communication between members in a software project and makes it easier for an IT manager in conducting management on Github project.
\end{abstract}

Keywords: Software project management, GitHub, notification, SMS

Abstrak - Manajemen proyek Perangkat lunak adalah seni dan ilmu perencanaan dan pembimbingan dalam proyek perangkat lunak. Pada manajemen proyek perangkat lunak banyak muncul kendala-kendala yang dapat mengakibatkan lamanya pembangunan dan pengembangan perangkat lunak. Salah satu poin penting dalam sebuah repositori proyek perangkat lunak adalah waktu yang dibutuhkan untuk mengomentari, menambahkan dan menggabungkan source code. Feedback yang cepat membuat anggota-anggota tim proyek perangkat lunak merasa senang untuk berkontribusi dalam sebuah proyek perangkat lunak. Permasalahan pada repositori Github adalah ketika notifikasi yang disampaikan lewat web dan email tidak langsung ditanggapi karena anggota-anggota proyek manajemen perangkat lunak jarang memeriksa email. Metode yang digunakan dalam penelitian ini adalah eksperimen dan studi pustaka dari berbagai kasus dalam artikel, buku atau paper yang membahas bagaimana melaksanakan manajemen proyek perangkat lunak yang berkualitas sehingga tujuan proyek perangkat lunak dapat dicapai. Kesimpulan hasil penelitian yang telah dilakukan adalah dengan menerapkan notifikasi SMS pada Github diharapkan dapat lebih mempercepat interaksi dan komunikasi antar anggota dalam sebuah proyek perangkat lunak serta mempermudah seorang IT manager dalam melakukan manajemen pada Github project.

Keywords: Software project management, GitHub, notifikasi, SMS 


\section{PENDAHULUAN}

Manajemen proyek Perangkat lunak adalah seni dan ilmu perencanaan dan pembimbingan dalam proyek perangkat lunak (Stellman \& Greene, 2006).

Perangkat lunak merupakan produk tidak berwujud sehingga dibutuhkan pengetahuan membuat perangkat lunak yang baik dan efisien dengan pendekatan teknik. Manajemen proyek perangkat lunak merupakan bagian yang penting dalam pembanguan perangkat lunak (Pressman, 2001).

$$
\text { Pada manajemen proyek }
$$

perangkat lunak banyak muncul kendala-kendala yang dapat mengakibatkan panjangnya lead time yang dibutuhkan untuk menerbitkan sebuah dokumen. Kendala-kendala tersebut adalah sebagai berikut:

- Delay dalam hal pengumpulan hasil uji terima dari lapangan yang disebabkan oleh jarak dan pengiriman, yang dapat mengakibatkan terjadinya penumpukan (bursting) dokumen di belakang

- Banyaknya dokumen yang harus diproses dalam waktu yang hampir bersamaan.

- Proses dokumentasi masih bersifat manual, baik dalam penyusunan maupun pemeriksaan awal.

Banyaknya lembaran dokumen yang harus melalui proses approval dan inisiasi pejabat terkait sehingga membutuhkan waktu dan effort yang tidak sedikit. Untuk mengatasi masalah tersebut dibuatlah suatu system yang dapat membuat simplifikasi proses dengan aplikasi berbasis automatisasi $I T$ Platform untuk peningkatan akurasi dan akuntibilitas pada setiap titik proses.

Tool yang akan digunakan dalam hal ini adalah GIT yang diharapkan dapat meminimalisir terjadinya hambatan-hambatan di atas.
Sistem ini akan memonitor dan mengintegrasikan proyek sejak awal proyek sehingga diharapkan dengan adanya system ini akan mempercepat lead time dari proses eksisting yang berjalan dan akan meningkatkan efisiensi dalam hal penggunaan kertas, tinta printer dan waktu yang dibutuhkan oleh para pejabat berwenang untuk melakukan approval (Rizal, 2014).

\section{Git}

Git adalah perangkat lunak pengontrol versi atau proyek manajemen kode perangkat lunak yang diciptakan oleh Linus Torvalds, yang pada awalnya ditujukan untuk pengembangan kernel Linux. Desain Git terinspirasi oleh BitKeeper dan Monotone. Git pada awalnya hanya dirancang sebagai mesin tingkat rendah yang dapat digunakan oleh tampilan muka (front end) lain seperti Cogito atau StGIT. Namun selanjutnya proyek inti Git telah berkembang menjadi pengontrol revisi lengkap yang dapat digunakan langsung. Saat ini, beberapa perangkat lunak terkenal menggunakan Git sebagai pengontrol revisinya, antara lain kernel Linux, Server X.org, pengembangan inti OLPC (One Laptop per Child), serta kerangka kerja web Ruby on Rails Pemeliharaan perangkat lunak Git saat ini diawasi oleh Junio Hamano. Dirilis di bawah Lisensi Publik Umum GNU versi 2, Git adalah suatu perangkat lunak bebas (Wikipedia, 2013).

\section{Github}

Github adalah software Hosting untuk proyek open source yang menggunakan Tool System revisi kontrol Git. Jadi Git adalah tool untuk melakukan revisi code, sedangkan github adalah webhostingnya. Mudahnya Github adalah Webhosting untuk proyek-proyek software seperti Google code atau sourceforge.net. Dalam bahasa gaul, Github adalah jejaring sosial untuk software developer (Putra, 2014). 
Yang membedakan Github dari Project hosting yang lain bisa kita lihat di bawah ini :

1. Github menggunakan Git sebagai tool utama dalam merevisi code.

2. Github menyediakan free hosting untuk proyek open source, namun Github juga menawarkan hosting berbayar untuk proyek perusahaan atau pribadi yang sifatnya privat.

3. Github ditargetkan untuk para developer yang bekerja secara tim dan tidak disatu tempat.

4. Github mempunyai fitur Social seperti Twitter seperti follow atau favorit (Star).

5. Github mendukung semua bahasa pemrograman, anda bebas memakai bahasa dan tool yang biasa anda pakai.

Beberapa fitur Sosial di Github:

1. Github user profile.

2. Follow, Kita bisa memfollow profil progammer lain di github.

3. Star, fungsinya sama dengan Bookmark.

4. Watch, memonitor repository tertentu. Setiap ada perubahan di Repo, maka kita akan dikirim notifikasi.

5. Fork, mengcopy keseluruhan code repository ke repo kita sendiri.

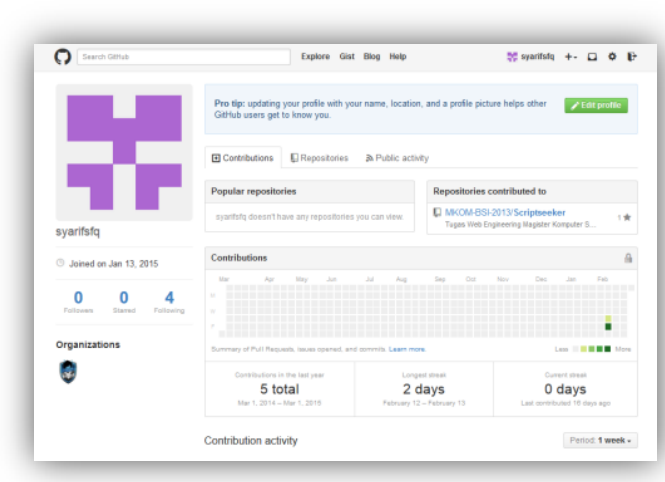

Gambar 1

Github Profile
Sama seperti Twitter, Github juga mempunyai profil. Profil berisi foto, jumlah repo yang dimiliki, jumlah follower, jumlah user yang kita follow dan Star (jumlah proyek yang kita beri tanda bintang).

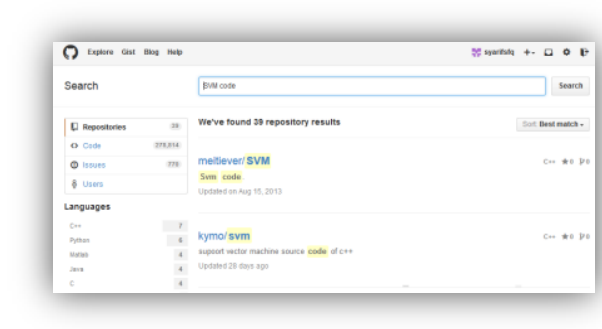

Gambar 2

Fitur Pencarian

Github mempunyai lebih dari 10 juta repo sofware. Jika anda ingin mencari proyek open source tertentu, gunakan fitur pencarian, hasil pencarian tampak seperti di gambar 2 diatas. Untuk memperkecil hasil pencarian bisa di filter berdasarkan Repo, code, issue atau nama user atau bahasa pemrograman. Hasil pencarian bisa diurutkan berdasarkan jumlah bintang tau jumlah "fork". Biasanya makin banyak bintangnya, makin berkualitas source codenya.

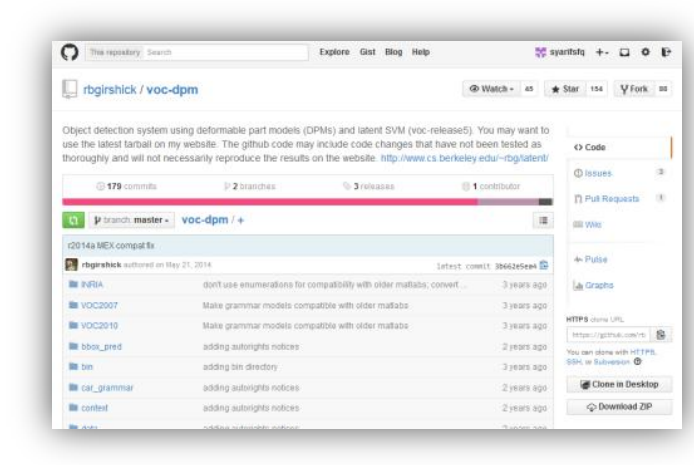

Gambar 3

Struktur Halaman proyek di Github

Contoh di gambar 3 adalah struktur poyek dari Object detection system using deformable part models (DPMs) and latent SVM (voc-release5). Mari kita analisa satu persatu struktur halamannya. 


\section{Bagian Statistik}

Bagian pertama adalah statistik, kia bisa melihat jumlah Watch, star dan fork dibagian atas halaman.

\section{Bagian Code}

Bagian utama dari struktur proyek ini adalah code itu sendiri. Kode ini juga berisi penjelasan kapan dan apa file terakhir yang diedit berserta penjelasan perubahan apa yang terjadi.

\section{Bagian Clone dan Download}

Clone in desktop di pakai untuk mengkopi source code proyek terserbut ke komputer kita , namun komputer kita harus sudah terinstall Github for Windows atau Mac. Bagian paling penting dan paling sering dipakai adalah menu DOWNLOAD. jika anda ingin langsung mencoba code di komputer , cukup klik download, maka source code otomatis akan di-zip dan diunduh ke kompuer anda.

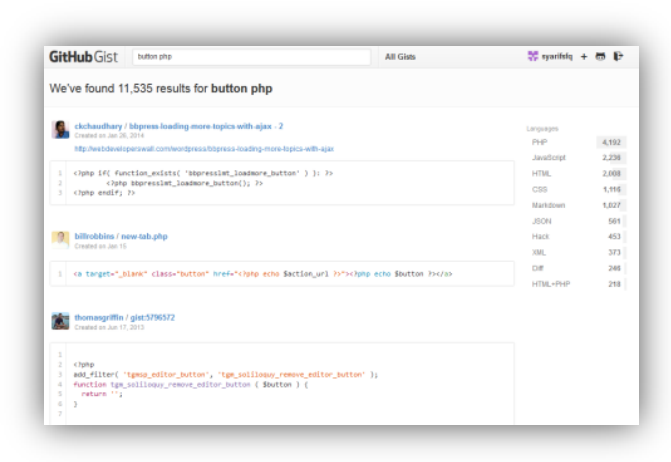

Gambar 4

\section{Contoh pencarian snipet code di Github Gist}

Github Gist adalah layanan share snippet dari github. Biasanya hanya potongan code pendek untuk memecahkan solusi di bahasa pemrograman tertentu. Sebagai contoh, anda ingin tahu bagaimana cara membuat tombol di php, anda cukup buka https://gist.github.com. lalu masukan query "button php".

\section{METODE PENELITIAN}

Metode yang digunakan dalam penelitian ini adalah eksperimen dan studi pustaka dari berbagai kasus dalam artikel, buku atau paper yang membahas bagaimana melaksanakan manajemen proyek perangkat lunak yang berkualitas sesuai dengan tujuan yang ditetapkan sehingga menghasilkan analisis deskriptif untuk menentukan masalah. Dan pendekatan pada penelitian ini adalah pendekatan secara general empiris berdasarkan pengalaman dan teori-teori yang berkaitan dengan manajemen proyek khususnya pada proyek perangkat lunak (Primawati \& Mustari, 2013).

\section{PEMBAHASAN}

Pengembangan perangkat lunak merupakan suatu yang penuh dengan tantangan. Sistem dibangun dengan kolaborasi antar anggota tim. Satu kunci penting bagi developer dalam kolaborasi membangun aplikasi adalah sesegera mungkin membuat comment dan menggabungkan permintaan ke dalam project pada Github Project.

Notifikasi Feedback dalam project sangat penting bagi developer atau IT manager namun sayangnya seringkali notifikasi yang dikirim lewat email terlewatkan karena jarang memeriksa email.

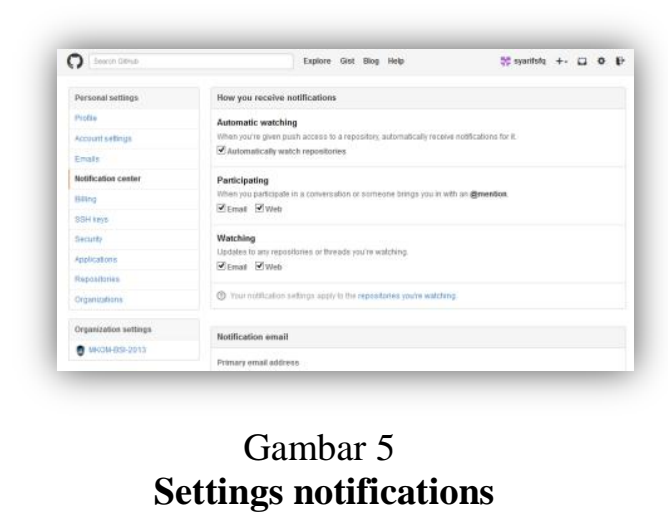

Dalam setting notifikasi Github hanya terdapat option pilihan email dan web. Dengan mengkombinasikan Zapier dengan Twilio kita dapat membuat 
notifikasi SMS untuk Github tanpa harus menulis source code sendiri.

\section{Daftar Twilio untuk mengirim SMS}

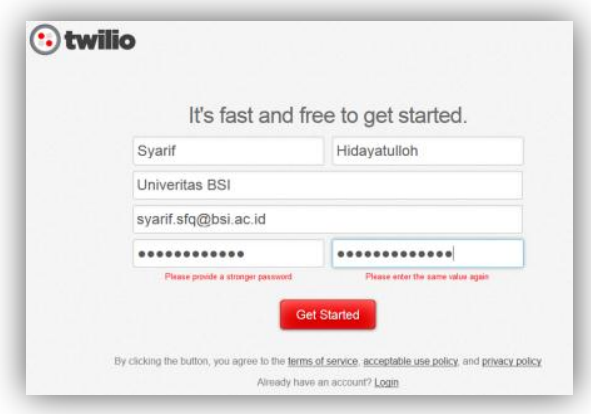

Gambar 6

Daftar Twilio

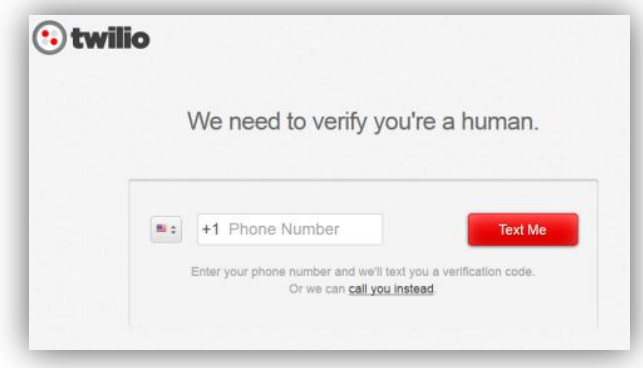

Gambar 7

Verifikasi Nomor Telepon

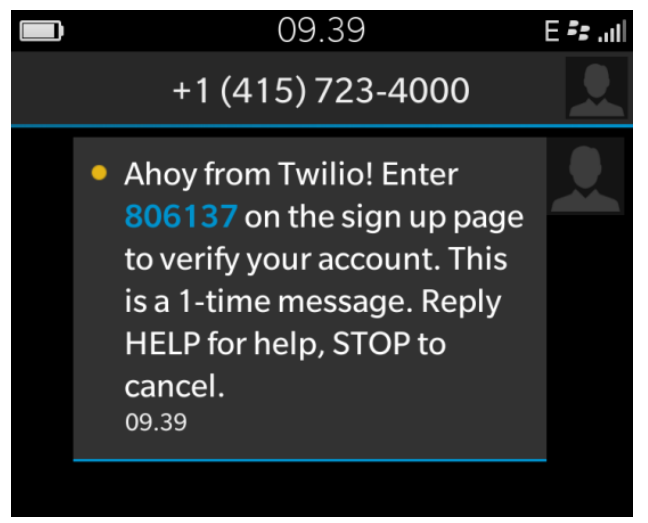

Gambar 8

Pesan verifikasi SMS dari Twilio

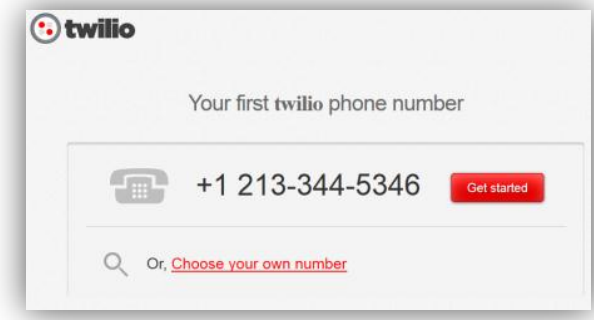

\section{Gambar 9}

Nomor telepon Twilio kita

Twilio akan memberikan nomor telepon secara random setelah proses pendaftaran selesai.

\section{Setting Zap dengan Zapier}

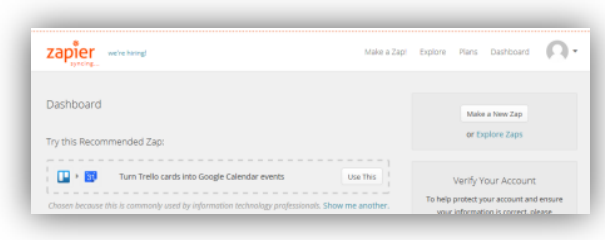

Gambar 10

Membuat Zap

Tekan tombol make new zap untuk membuat zap.

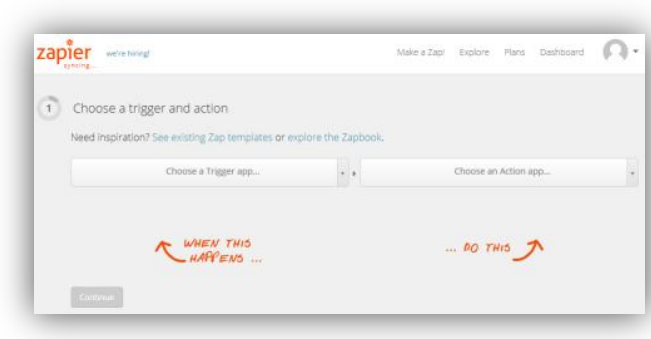

Gambar 11

Memilih trigger and action

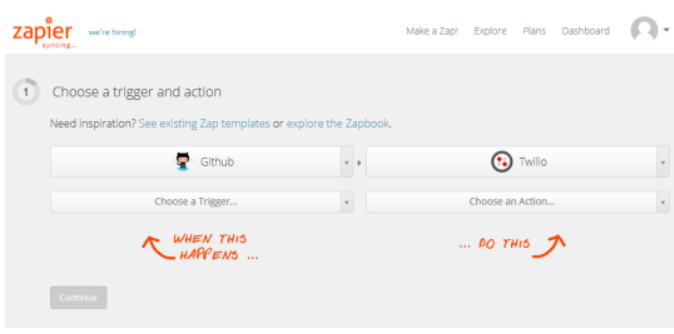

Gambar 12

Memilih trigger dan action 


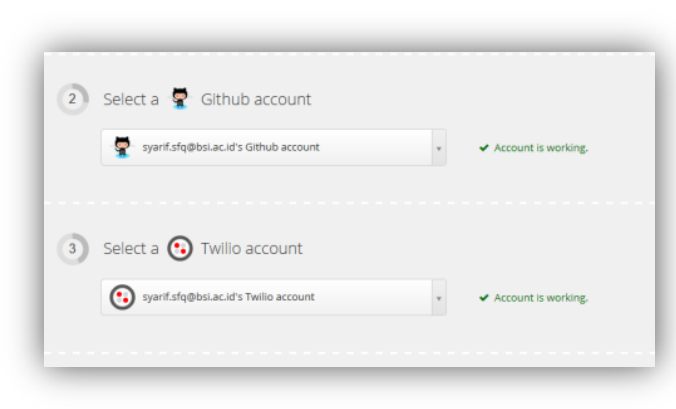

Gambar 13

Zapier berhasil terkoneksi dengan Github dan Twilio

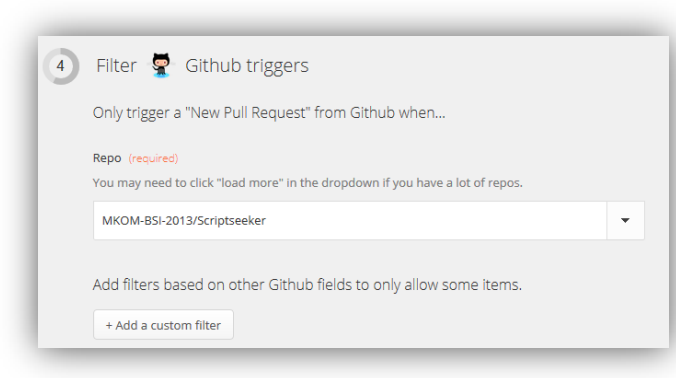

Gambar 14

Menentukan repositori Github project

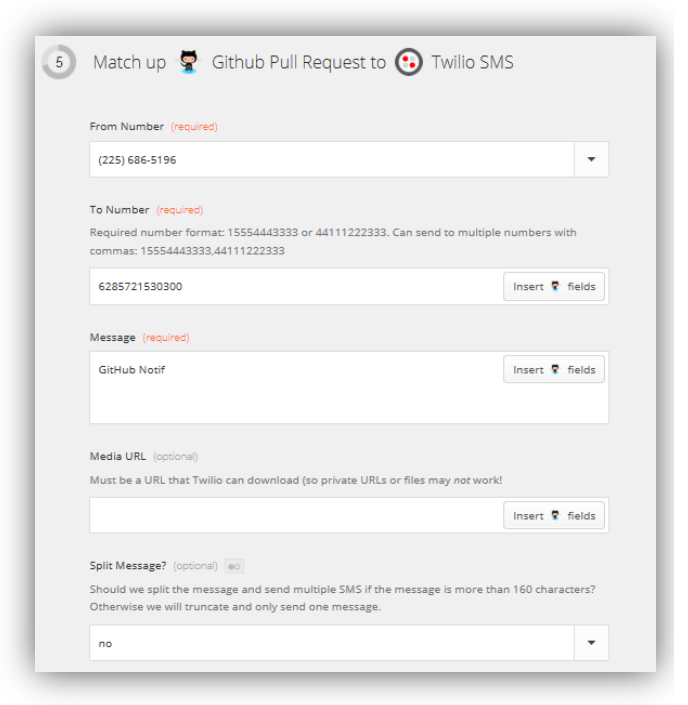

Gambar 15

Menambahkan pesan tambahan pada notifikasi SMS

Terakhir, pilih nomor telepon Twilio untuk mengirim notifikasi. Kita juga dapat menambahkan pesan tambahan namun tidak lebih dari 160 karakter.

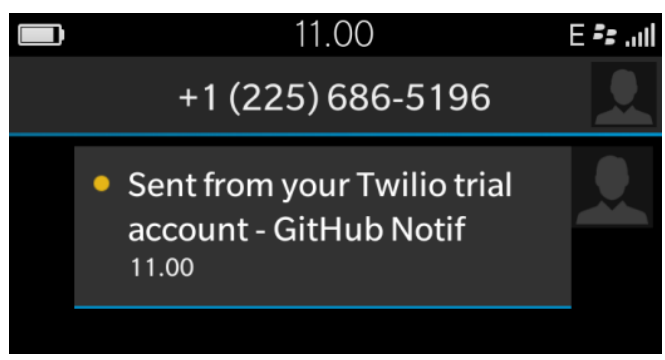

Gambar 16

Hasil notifikasi SMS

\section{KESIMPULAN}

Berdasarkan penelitian yang telah dilakukan, maka dapat diambil beberapa kesimpulan sebagai berikut.

1. Fitur Notifikasi pada Github kurang variatif sehingga perlu adanya penambahan fitur.

2. Mempermudah seorang IT manager dalam melakukan manajemen pada Github project.

3. Dengan menerapkan notifikasi SMS pada Github diharapkan dapat lebih mempercepat interaksi dan komunikasi antar anggota dalam sebuat Project.

\section{REFERENSI}

Pressman, R. S. (2001). Software Engineering : A Practioner's Approach." 5th. McGrawHill.

Primawati, A., \& Mustari, D. (2013). ANALISIS MANAJEMEN PROYEK PERANGKAT LUNAK SISTEM INFORMASI AKUNTANSI PADA BIRO SISTEM INFORMASI PT. $X$. Journal of Information Systems Vol.9, Issue.2, 101-106.

Putra, C. A. (2014, Januari 25). Pengenalan Github untuk pemula. Retrieved from candra.web.id: http://www.candra.web.id/2014/ 
01/25/pengenalan-github-untukpemula/

Rizal, A. (2014). Analisis Penerapan Project Management Information System (PMIS) Menggunakan Metode Technology Acceptance Model (TAM) Studi Kasus PT. INDOSAT, Tbk . IncomTech Vol.5, No.1 ISSN 2085-4811, 124.

Stellman, A., \& Greene, J. (2006). Applied Software Project Management. california: O'Reilly Media, Inc.

Wikipedia. (2013, April 6). Git. Retrieved from wikipedia: http://id.wikipedia.org/wiki/Git 